\title{
A Study of Genetic Polymorphism of Crithidia in Isfahan, Iran
}

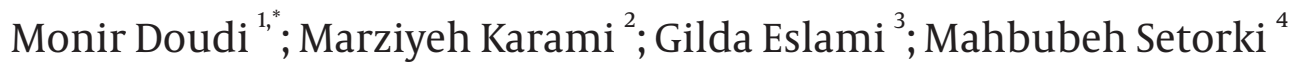 \\ ${ }^{1}$ Department of Microbiology, Falavarjan Branch, Islamic Azad University, Isfahan, IR Iran \\ ${ }_{2}^{2}$ Young Researchers Club, Falavarjan Branch, Islamic Azad University, Isfahan, IR Iran \\ ${ }^{3}$ Department of Parasitology and Mycology, Shahid Sadoughi University of Medical Sciences, Yazd, IR Iran \\ 4 Department of Biology, Izeh Branch, Islamic Azad University, Izeh, IR Iran \\ *Corresponding author: Monir Doudi, Department of Microbiology, Falavarjan Branch, Islamic Azad University, Isfahan, Iran. E-mail: doudi@iaufala.ac.ir
}

Received: February 17, 2014; Accepted: May 2, 2014

\begin{abstract}
Background: Genotyping of Crithidia species is critical in order to design appropriate programs for control and prevention of cutaneous leishmaniasis $(\mathrm{CL})$.

Objectives: The purpose of this project was study and investigation genetic polymorphism of Crithidia in Isfahan city.

Patients and Methods: In this descriptive-analytical study, 602 samples were isolated from suspicious patients with cutaneous leishmaniasis who referred to Leishmaniasis Research Center or other health centers in the vicinity of Isfahan. After culturing of the samples in NNN (Novy MacNeal Nicole, (C) Merck) medium, DNA extraction was performed. Molecular detection and identification was done using PCR-RFLP technique.

Results: Results showed that 50 samples (8.31\%) were negative. Out of 201 samples (33.39\%) were Crithidia Spp which 27 cases (13.44\%) were Crithidia fasciculata,11 cases (5.47\%) were Crithidia luciliae and the rest(163 cases or 81.9\%) were similar to Trypanosomatidae which submitted at gen bank with accession number of GQ331988. BLAST showed that the last ones have $92 \%$ and $89 \%$ similarity to C. fasciculata and C. luciliae, respectively. Out of 351 patients (58.31\%) identified as Leishmania spp.

Conclusions: The results of the present study suggested that there is some recombinant species in Isfahan and surrounding area that could be an important agent of cutaneous leishmaniasis.
\end{abstract}

Keywords: Polymorphism; Crithidia; Internal Transcribed Spacer 1(ITS1); Polymerase chain reaction - Restriction Fragment Length Polymorphism (PCR-RFLP)

\section{Background}

Blood and tissue flagellates are a wide range of protozoan parasites, which are, at least in one of the evolutionary stages of flagellum. Blood and tissue flagellates consist of 1-4 forms in a protozoan life cycle, which are the following: 1-Promastigote (Leptomonas pessoai), 2- Epimastigote (Crithidial form), 3- Trypomastigote (Trypanosomiasis), 4Amastigote (Leishman body) [1].

Crithidias are considered as insect parasites; however, since in gene sequences of rRNA they are close to leishmania, most often they accompany and are mistaken with leishmania [2]. Crithidia oncopelti is isolated from a sap-feeding insect (presumably the plant Oncopeltus fasciatus), Crithidia deanei is isolated from a predatory insect called Zelus leucogrammus and Crithidia desouzaii from a nectar-feeding fly named Orinidia Obesa [3-5]. Crithidia luciliae and C. fasciculata are not only insect parasites, but also are considered as the infecting agents of leishmania cultivation [2]. During the past 20 years, a variety of methods have been developed to identify different sub-species of leishmania and Crithidia, and study the molecular diversity and mutual influences of parasites and host [6-8]. It is worth mentioning that methods with the following features must be used for the distinction and differentiation of species that are very close together: 1 - They should be practical, 2 - be done quickly, 3- be cost-effective 4- do not require special skills. During recent years, various genetic and molecular techniques to isolate the pathogenic strains of diseases have become important in epidemiological and clinical studies and the study of other infectious diseases. Developments of molecular techniques using molecular markers and different polymerase chain reaction (PCR) methods have been reported for phylogenetic differentiation and identification of parasites [9]. In the recent decade, many of the studied molecular markers for the polymerase chain reaction (PCR) were: Microsatellite DNA, Kinetoplastic DNA (KDNA), Telomeric sequences, or genes such as gp63, hsp70, mini-ex-

Copyright (C) 2015, Zahedan University of Medical Sciences. This is an open-access article distributed under the terms of the Creative Commons Attribution-NonCommercial 4.0 International License (http://creativecommons.org/licenses/by-nc/4.0/) which permits copy and redistribute the material just in noncommercial usages, provided the original work is properly cited. 
on, tubulin $\beta$, and/or ribosomal RNA genes. Among the above mentioned RFLP (Restriction fragment length polymorphism) techniques related to PCR, amplified sequences corresponding to internal transcribed spacer (ITS) gene have suggested promising results [10, 11]. Consequently, it is an appropriate method to investigate phylogenic polymorphism and relationship between organisms. ITS sequence analysis can show the phylogenic relationship of many parasites [12,13]. The structure of ribosomal gene locus has two DNA areas which encode the small subunit of 18s SSU rRNA and the large subunit of 28s LSU rRNA. At the 5'-end region of the 18s, there is a fragment named ETS (External Transcribed Sequences) which continues from 5'-end to the promoter sequence $[14,15]$.

The PCR-RFLP technique is a sensitive and specific tool for detection and identification. In this technique, the types of endonucleases are used that are able to detect specific nucleotide sequences on DNA organic sequences bases and restriction of the deoxyribonucleic acid (DNA) specifically or non-specifically. Restriction of these enzymes provides DNA fragments in different sizes and comparing these fragments in various isolations can provide a more accurate estimation of sequence difference of DNA in various isolations $[16,17]$. This research project aimed to review different genotypic Crithidia through PCR and RFLP with the help of ITS1 gene sequences.

\section{Objectives}

This infectious agent is genetically polymorphism and it was hypothesized that there could be a probable correlation between the prevalence rate of the infection and genotypic variations of the studied stains and also their geographic origin.

\section{Patients and Methods}

\subsection{Patients and Study Region}

This study was descriptive-analytical and carried out in Isfahan and its surrounding areas, located in the central part of Iran. There were 201 study samples. Sampling started from 21 March 2011 to 21 November 2011 (for 8 months). The selected cutaneous leishmaniasis lesions (wounds) in the patients had various forms.

Sample collection and preparation: First, the lesions were sterilized using 70\% ethanol and saline serum, and then following a local anesthesia, xylocaine solution was used for them. Thereafter, surface cuts of 2 to $3 \mathrm{~mm}$ were made on the edges of the lesions and then the prepared restrictions were impregnated into the Brain Heart Infusion Broth (BHI medium, (CMerck) and sterilized in $4^{\circ} \mathrm{C}$ or saline solution as the medium and then were transferred into cultured medium NNN (Novy Mac Neal Ni- cole, (CMerck) close to the flame and finally were placed in incubator in $24 \pm 2{ }^{\circ} \mathrm{C}$.

Isolation and culture: As mentioned earlier, liquid BHI mediums containing species were also transferred close to flames in sterile conditions in NNN medium in 24 $\pm 2{ }^{\circ} \mathrm{C}$ and were examined every three days for 6 weeks before any negative report. Then, the amplified promastigotes were transferred and amplified in culture medium RPMI 1640 with 10\% FCS (Sigma). At the late stage of logarithmic growth $(5 \times 106$ parasites $/ \mathrm{mL})$, isolated species were taken out and were sterilized with saline solution in phosphate buffer (PBS) and were washed with centrifuge $\mathrm{pH}=7.4$ and were moved to a freezer in $-70^{\circ} \mathrm{C}$ for further tests and examinations. The reference strains used in this study were: Crithidia luciliae and Crithidia fasciculata.

DNA extraction: Suspension of promastigotes of the 2 washed Leishmania and Crithidia isolates in the previous stage with $5 \times 106$ parasites $/ \mathrm{mL}$ were taken out of $-70^{\circ} \mathrm{C}$ freezer. Two hundred microliters of Binding Buffer and $40 \mu \mathrm{L}$ of proteinase $\mathrm{K}$ were added to its precipitation, and the contents were placed in a water bath (bain-marie) for $10 \mathrm{~min}$ in $70^{\circ} \mathrm{C}$. The rest of the stages were done according to kit's instruction (High pure PCR Template Preparation kit, Roche). Finally, DNA was dissolved in $200 \mu \mathrm{L}$ of elution buffer. The extracted DNA was studied quantitatively and qualitatively by spectrophotometry, and then agarose gel $0.8 \%$ in TBE $1 \times$ buffer.

Amplification of ITS1 using PCR: Amplification of ITS1 using PCR was conducted through the LITSr primers L5.8S with the following sequences:

LITSr (5'-CTGGATCATTTTCCGATG-3') L5.8s (5'-TGATACCACTTATCGCACTT-3')

The best condition for implementing PCR was determined by using the standard strains. The reaction was performed in $25 \mu \mathrm{L}$. First, a Master Mix was prepared which consisted of $0.2 \mu \mathrm{L}$ of Taq polymerase (50 Mm), 2 $\mu \mathrm{L} \mathrm{Mgcl} 2$, R and F primers with concentration of 10 picomoles $1 \mu \mathrm{L}$ of each, $2 \mu \mathrm{L}$ PCR10x Buffer, dNTPs (10 Mm) for 1 $\mu \mathrm{L}$, and finally $1 \mu \mathrm{L}$ extracted DNA was added to the above mentioned items, and the final volume of the distilled water reached $25 \mu \mathrm{L}$. The samples were placed into the thermocycler device (Corbett, Australia) and the following cycles were performed for the PCR implementation:

Thereafter, the PCR products with positive and negative controlling along with molecular marker of 50 bp were placed on $1.5 \%$ agasore gel containing $0.7 \mu \mathrm{g} / \mathrm{mL}$ ethidium bromide per $\mathrm{ml}$ of gel in TBE $1 \times$ buffer and then were electrophoresed for 25-45 minutes in a voltage of $80 \mathrm{~V}$. The PCR products were observed in transilluminator device using UV lamp [18].

RFLP analysis for amplified ITS1: In order to detection of the genus, the products of ITS1-PCR were digested under the effect of restriction enzyme HaeIII (Fermentas) and the related buffer in $37^{\circ} \mathrm{C}$ for 2 hours. Analysis of the digestion was done using $2 \%$ agarose gel electrophoresis in TBE $1 \times$ buffer under $5 \mathrm{v} / \mathrm{cm}$. Molecular iden- 
Doudi M et al.

tification was performed using RFLP withrestriction enzymes of TaqI, ScrFI and DdeI. All of the digestions were compared with the standard strains of Crithidia and Leishamnia [18].

DNA sequencing: Samples with different patterns of RFLP were purified and sequenced. Then, BLAST analysis was done for sequenced samples.

Statistical analysis: Finally, the collected data were analyzed using descriptive statistics and $\chi 2$ test in SPSS-16.0 (SPSS Inc., Chicago, IL, USA). P-Values less than 0.05 were considered significant.

\section{Results}

This 8-month study was carried out on 602 patients with wet CL who referred to the Isfahan Leishmaniasis Research Center or other health centers in the vicinity of Isfahan. Culturing in NNN medium, DNA extraction from promastigotes, implementation of the PCR-RFLP method, amplification of ITS-1, and application of the HaeIII enzyme were carried out. As a result, 201 patients (33.39\%) were found with two species of Crithidia; 27 cases of Crithidia fasciculata (13.44\%) and 11 cases of Crithidia luciliae (5.47\%).

The rest, however, were trypanosomatidae with Accession number of GQ331988; molecular analysis showed that $92 \%$ had a tendency of homology with C. fasciculata and $89 \%$ with C. luciliae (163 cases or $81.9 \%$ ). Out of 351 patients (58.31\%), leishmaniasis parasite was isolated, and out of 50 patients (8.31\%), neither Leishmaniasis nor Crithidia were isolated. Therefore, their report was negative following cultured samples. The results of the present study showed that of the 201 patients studied in these two areas, 103 of them (51.24\%) were related to Isfahan and 98 samples $(48.76 \%)$ were related to the surrounding areas of Isfahan $(\mathrm{P}=0.001)$.

The results of PCR-RFLP analysis in Isfahan and surrounding areas with HaeIII enzyme restriction suggested that a number of isolated species showed a single-band at $350 \mathrm{bp}$, which was related to the leishmania species. Moreover, a number of them showed no band which was neither Leishmania nor Crithidia. A number of them also manifested a single-band at $400 \mathrm{bp}$ and many other isolated species showed single-band at 450 bp.

Finally, a large number of isolated species showed two bands at 400 and $450 \mathrm{bp}$; the last three groups are related to the trypanosomatidae family (Figure 1).

It should be mentioned that the last three groups, which were related to the trypanosomatidae family, had no difference in restriction enzymes compared with standard species after restriction with other enzymes (DdeI, ScrFI, and TaqI) (Figures 2, 3, 4).

The generated band profiles after the effect of DdeI, ScrFI, and TaqI enzymes on isolations with bands at 450 and 400 bp and two bands of 400 and 450 bp simultaneous included:
Figure 1. Band profiles generated from DNA genome isolated with the enzyme HaelII through PCR-RFLP method

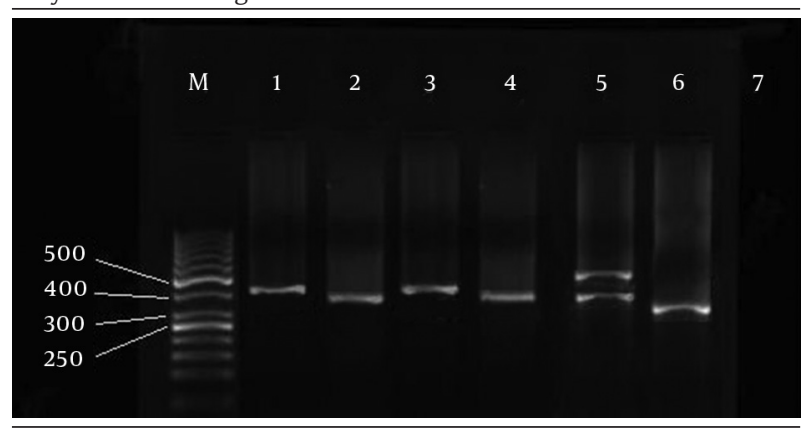

M, Molecular marker at $50 \mathrm{bp}$, line 1, Standard C. fasciculata, Line 2, Standard C. luciliae, Line 3, Isolated consistent with C. fasciculata, line 4, Isolated consistent with C. luciliae, line 5, Isolated non-consistent with the two standard samples of C. luciliae and C. fasciculata, line 6, Leishmania genus, Line 7, Negative control

Figure 2. Band Profiles generated From DNA Genome Samples Consistent with C. fasciculata at 450 bp Through PCR-RFLP With DdeI, ScrFI, and TaqI Enzymes

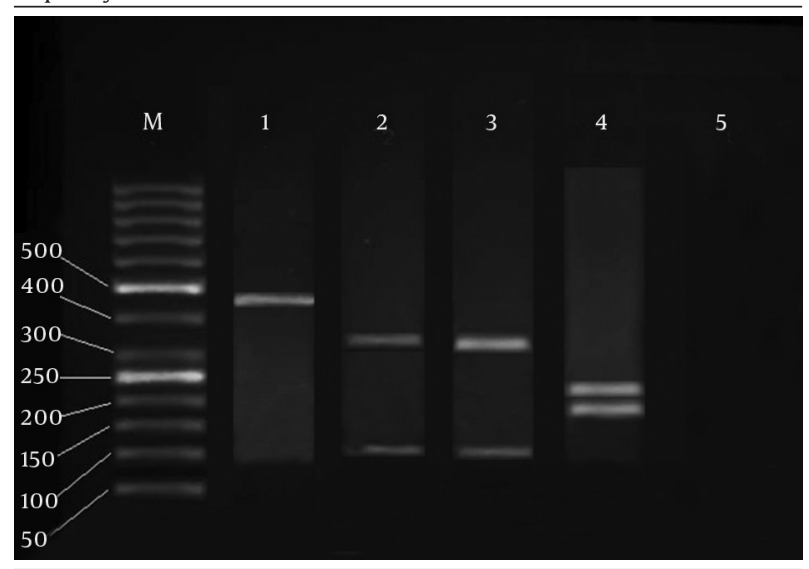

M, Molecular marker at 50 bp, Line 1, Standard C. fasciculata Line 2, Band profiles generated by DdeI enzyme, Line 3, Band profiles generated by ScrFI enzyme, Line 4, Band profiles generated by TaqI enzyme, Line 5 , Negative control.

Figure 3. Band Profiles generated From DNA Genome Samples Consistent with C. luciliae at 400 bp Through PCR-RFLP With DdeI, ScrFI, and TaqI Enzymes

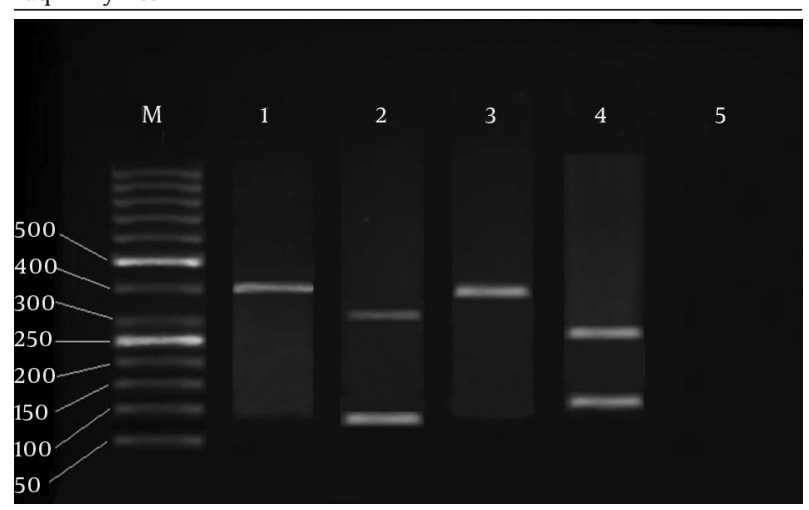

M, Molecular marker at 50 bp, Line 1, Standard C. luciliae, Line 2, Band profiles generated by DdeI enzyme, Line 3, Band profiles generated by ScrFI enzyme, Line 4, Band profiles generated by TaqI enzyme, Line 5, Negative control. 
Doudi M et al.

Following the effect of the DdeI enzyme on all the isolations with band at $400 \mathrm{bp}$, fragments of 307 and $92 \mathrm{bp}$ were observed. Following the effect of the ScrFI enzyme on all the isolations with band at $400 \mathrm{bp}$, no fragment was observed. On the other hand, after the effect of the TaqI enzyme on all isolations with band at $400 \mathrm{bp}$, fragments of 275 and 124 bp were observed.

Following the effect of the DdeI enzyme on all isolations with band at $450 \mathrm{bp}$, fragments of 331 and $115 \mathrm{bp}$ were observed.

Following the effect of the ScrFI enzyme on all isolations with band at $450 \mathrm{bp}$, fragments of 321 and $125 \mathrm{bp}$ were observed.

On the other hand, after the effect of the TaqI enzyme on all isolations with band at $450 \mathrm{bp}$, fragments of 217 and 229 bp were observed.

Furthermore, after the effect of the DdeI enzyme on all isolations with the two bands at 400 and $450 \mathrm{bp}$, fragments of 334 and 115 bp were observed. Moreover, after the effect of the ScrFI enzyme on all isolations with the two bands at 400 and 450 bp, fragments of 323 and 126 bp were observed.

On the other hand, following the effect of the TaqI enzyme on all isolations with the two bands at 400 and 450 bp, fragments of 301 and $148 \mathrm{bp}$ were observed.

For genotyping the isolation of trypanosomatidae, the enzyme profiles of which have shown a non-compliance restriction with the standard species, these samples were transferred to Farapajooh Company in Tehran for sequencing, and then their sequences were identified by S. Korea. The results are illustrated in Figures 5 - 7. Crithidia phylogenetic analysis based on Gen Bank (Figure 8).

Figure 4. Band Profiles Generated From Non-Consistent DNA Genome with C. luciliae and C. fasciculata Standards at 400 and $450 \mathrm{bp}$

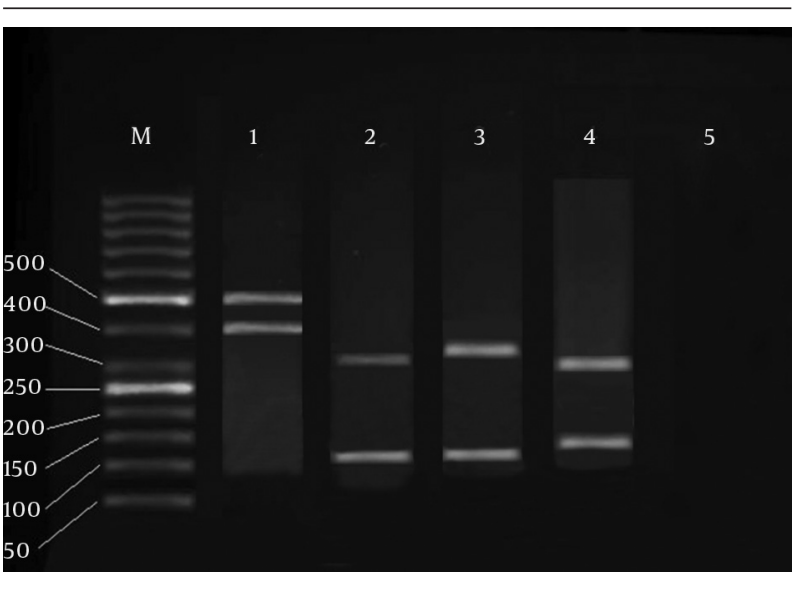

M, Molecular marker at $50 \mathrm{bp}$, Line 1, Non-consistent sample with C. luciliae and C. fasciculate standards, Line 2, Band profiles generated by Ddel enzyme, Line 3, Band profiles generated by ScrFI enzyme, Line 4, Band profiles generated by TaqI enzyme, Line 5, Negative control

Figure 5. Obtained Results From Sequencing the Partial ITS1 Gene Products in Isolations Consistent With the Standard species C. fasciculata (Accession Number emb | Y00055.1 |)

TTTCTCTCTCAACTCTCTCTCTTGTTGGGGGTGTTGTGTGTGGGGGTTTGTGCGCGCGGTGCCGGAACAAG GCCAATCGATGCACGTGTGTGTATTGTATTGTTCTTTCT

Crithidia fasciculata strain in MHOM/IR/90/H.

Figure 6. Obtained Results From Sequencing the Partial ITS1 Gene Products in Isolations Consistent With the Standard Species C. luciliae (Accession Number emb | AJ627018.1 | )

TTTCTCTCTCAACTCTCTCTCTTGTTGGGGGTGTTGTGTGTGGGGGTTTGTGCGCGCGGTGCCGGAACAAG GCCAATCGATGCACGTGTGTGTATTGTATTGTTCTTTCTT

Crithidia luciliae internal transcribed spacer.

Figure 7. Obtained Results From Sequencing the Partial ITS1 Gene Products in Isolations From a Species Consistent With Trypanosomatidae With the (Accession Number gb | GQ331988.1 | )

TTTCTCTCTCAACTCTCTCTTTTGTTGGGGGTGTTGTGTGTGGGGGTTTGTGCGCGCGGTGCCGGAACAAG GCCAATCGATGCACGTGTGTGTATTGTATTGTTCTTTCTT 


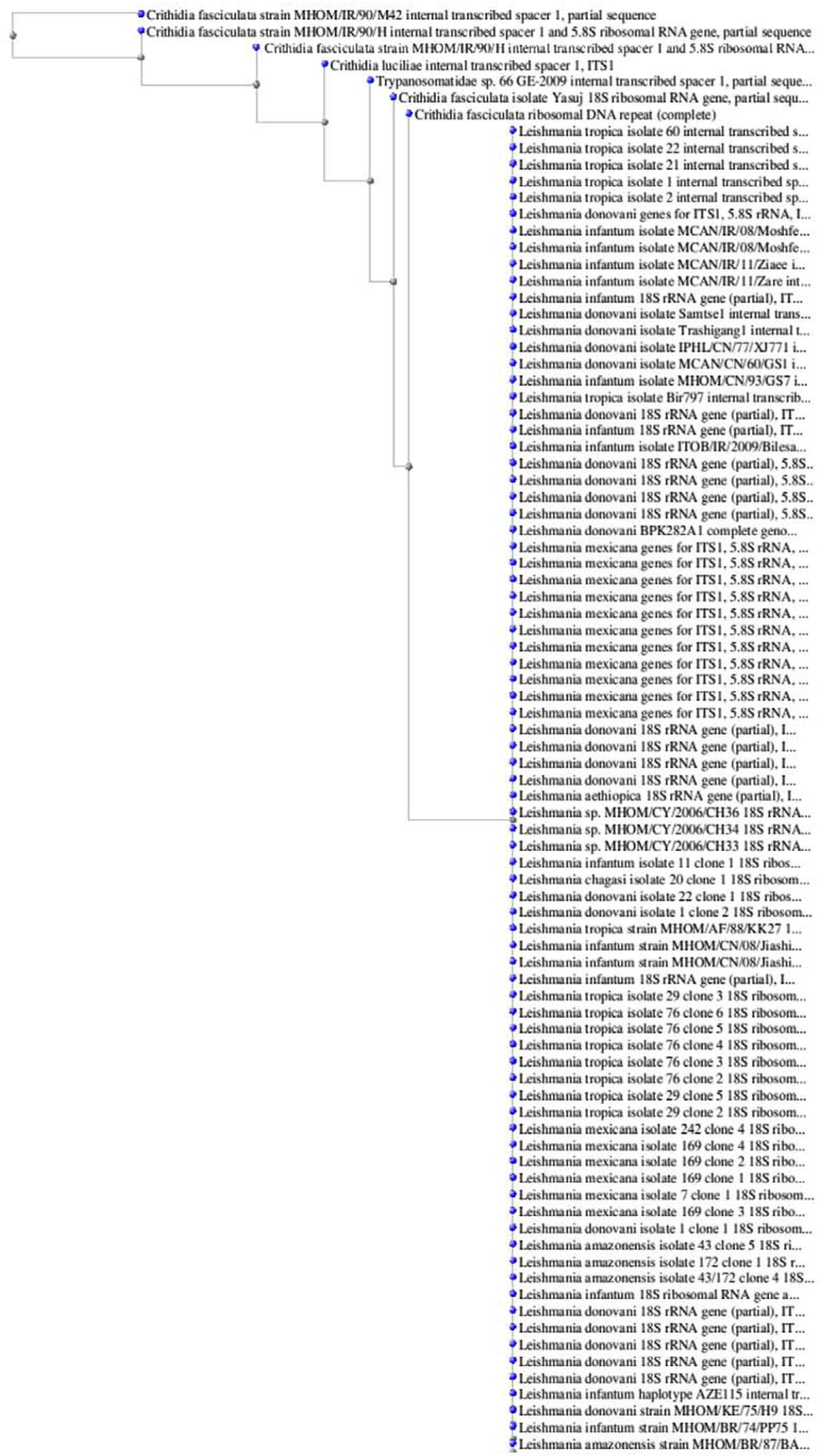

Figure 8. Crithidia Phylogenetic Analysis Based on Gen Bank, NCBI 


\section{Discussion}

According to the strategies for controlling cutaneous leishmaniasis in the hyper-endemic regions of Iran and the World Health Organization providing the vaccine to prevent this disease has been proposed [16]. Therefore, one of the basic requirements is the determination of specifications for the species of Crithidia, which unfortunately infects the parasite leishmania cultures and has makes it impossible to prepare a purified antigen from the parasite (genus of leishmania) for preparing the vaccine [17].

Marmur et al. suggested that Crithidia might be a protozoan, which can live within some bacteria such as Bordetella bronchiseptica as endosymbiosis. Furthermore, these researchers found that in addition to the mentioned bacteria, this parasite can also live within B. culicis as a symbiosis. Marmur has proved his results by studying the $r$ RNA ribosomal genes and SSURNA region, i.e. a part of ITS1 gene [4].

Wang et al. proposed that not only can Crithidia be isolated from bacteria such as B. bronchiseptica and B. eulicis in an endosymbiotic manner, but also they can be isolated from a mosquito called Aedesvexans; particularly in C. oncopelti from an insect feeding from Oncopeltus fasciatus, Crithidia deanei is isolated from a predatory insect called Zelus leucogrammus, and Crithidia desouzaii from a nectar-feeding fly called Orinidia obese. These researchers stated that a relationship between this protozoan and a large group of insects from the Depteran and reduviidae hemitran families has caused a great deal of interest about this protozoan [1].

The Crithidias are able to endosymbiotically live within some parasites related to the trypanosomatidae family, and sub-families of Leishmania, and move to different hosts along with them. These researchers believed that the only way to isolate Crithidia from Leishmania is through KDNA and/or rRNA genes. They suggested that by extraction of kinetoplast DNA and/or ribosomal DNA, then amplifying them with PCR, using the PCR-RFLP technique with HaeIII enzyme, and isolation of band at 350 bp for leishmania and at 450 bp for Crithidia these two parasites can be isolated from each other [18].

The results of the present study to some extent are in accordance with the results of the study by Yang et al. [19]. According to data, which illustrates the frequency distribution of isolated trypanosomatidae family from culturing in Isfahan and surrounding areas, a large number of samples, i.e. 163 samples (81.09\%), showed two bands of 400 and 450 bp after PCR. Using the Hea III enzyme, and after the random sequence of several samples, the results of the molecular analysis via the Software Blast showed 92\% homology with C. fasciculata and 89\% homology with C. luciliae. Moreover, the sequence of the mentioned gene was in accordance with the World Gene Bank with the Accession number of GQ331988 which has been indicated by Doudi et al. [2].
Berzunza-Cruz et al. stated that a great heterogeneity between different strains of leishmania and its family, i.e. trypanosomatidae, can be found by using PCR-RFLP technique, to which different species show various differences [10]. In this study, by using the molecular PCR-RFLP method, applying Hae III enzyme according to figure 1 and by the generated band profiles formed by the isolated genome we concluded that there was a difference between various species of Crithidia in terms of difference of sequence in the transcribed region of ITS-1. This was in a way that all the isolations following PCR and applying HaeIII enzyme that had revealed the band at 450 bp were similar to the $C$. fasciculata in terms of ITS-1 gene sequence, and all the isolations following PCR and applying HaeIII enzyme that had revealed the band at $400 \mathrm{bp}$ were similar to C. luciliae in terms of ITS1 gene sequence.

Yang et al. [19] proposed that similar to many parasites, studying the phylogenetic relationships of different species of Leishmania and Crithidia parasites is extremely complicated. This is because defining and categorizing the subspecies in order to describe them is very hard. This group of researchers collected 17 isolated Leishmania and 2 isolated Crithidia from different areas of China and amplified the ITS1 ribosomal gene using the PCR technique. They then sequenced a number of these isolations in terms of taxonomy, and identified the phylogenetic affinities between species of Leishmania and other parasites [19]. However, it should be mentioned that no difference was observed in analyzing the band profiles using the Ddel, ScrFI and TaqI enzymes on all the isolations, compared with the standard samples. Therefore, it seems that Hae III enzyme played a key role in the isolation of the Crithidia species in this study.

In general, according to the results, it can be concluded that Crithidia, which has been studied for the first time in terms of genetic polymorphism in Iran and Isfahan, is relatively polymorphic. This genetic polymorphism in this parasite showed a direct relationship with PCR-RFLP patterns. However, since Leishmania major is related to the hyper-endemic regions, further studies are required for other geographical regions of Iran and their relationship with these patterns. The results of the present study can be used by physicians, particularly dermatologists, for the appropriate treatment of Cutaneous Leishmaniasis, and can provide a new way for preparing a vaccine for cutaneous leishmaniasis.

\section{Acknowledgements}

We would like to thank the esteemed staff of Isfahan Leishmaniasis Research Center (Sedigheh Tahereh Center) and the Research Laboratory of Islamic Azad University, Falavarjan Branch. Moreover, we truly appreciate the cooperation of the manager of the Sedigheh Tahereh Leishmaniasis Research Center, Dr. Nilforoushzadeh, and also Ms. Leila Shirani Bidabadi, Fereshteh Ghasemi, Shadi Shahsar and Somayeh Parsafar and would like to thank 
of project Exective Dr. Monir Doudi with code number 301/28205.

\section{Authors' Contributions}

All authors had equal role in design, work, statistical analysis and manuscript writing.

\section{Funding/Support}

Falavarjan Branch, Islamic Azad University.

\section{References}

1. Wang JR, Lee ST, Juan WH, Chuang WL, Hung SI, Chung WH, et al. Indigenous leishmaniasis in Taiwan: report of a case. Int J Dermatol. 2008;47(1):40-3.

2. Doudi M, Hejazi SH, Razavi MR, Narimani M, Khanjani S, Eslami G. Comparative molecular epidemiology of Leishmania major and Leishmania tropica by PCR-RFLP technique in hyper endemic cities of Isfahan and Bam, Iran. Med Sci Monit. 2010;16(11):CR530-5.

3. Krieg NR, Holt JG. Bergeys manual of systematic bacteriology.New York: Springer; 2001.

4. Marmur J, Cahoon ME, Shimura Y, Vogel HJ. Deoxyribonucleic Acid Type attributable to a Bacterial Endosymbiote in the Protozoon Crithidia (Strigomonas) oncopelti. Nature. 1963; 197(4873):1228-9.

5. Mundim MH, Roitman I, Hermans MA, Kitajima EW. Simple nutrition of Crithidia deanei, a reduviid trypanosomatid with an endosymbiont. J Protozool. 1974;21(4):518-21.

6. Cox F, Kreier JP, Wakelin D. Parasitology. In: Collier L, Balows A Sussman M, editors. Topley and Wilson's microbiology and microbial infections. 9th ed. UK: Hodder Education Publishers; 1998.

7. Alavinia S, Arzamani K, Reihani M, Jafari J. Some epidemiological aspects of cutaneous leishmaniasis in northern khorasan province, iran. Iran J Arthropod Borne Dis. 2009;3(2):50-4.

8. Banuls A, Brisse S, Sidibe I. A phylogenetic analysis by rnultilocus enzyme electrophoresis and multiprimer random amplified polymorphic DNA finger printing of the Leishmania ge- nome project Friedlin reference strain. Folia Parasitol (Praha). 1999;46(1):10-4.

9. Nahla OAET. Molecular approaches to direct diagnosis and characterization of Leishmania donovani in clinical isolates.Germany: Humboldt University; 2002.

10. Berzunza-Cruz M, Cabrera N, Crippa-Rossi M, Sosa Cabrera T, Perez-Montfort R, Becker I. Polymorphism analysis of the internal transcribed spacer and small subunit of ribosomal RNA genes of Leishmania mexicana. Parasitol Res. 2002;88(10):918-25.

11. Du Y, McLaughlin G, Chang KP.16S ribosomal DNA sequence identities of beta-proteobacterial endosymbionts in three Crithidia species. J Bacteriol. 1994;176(10):3081-4.

12. Tashakori M, Kuhls K, Al-Jawabreh A, Mauricio IL, Schonian G, Farajnia S, et al. Leishmania major: genetic heterogeneity of Iranian isolates by single-strand conformation polymorphism and sequence analysis of ribosomal DNA internal transcribed spacer. Acta Trop. 2006;98(1):52-8.

13. Kazemi Rad E, Mohebali M, Hajjaran H, Rezaei S, Mamishi S. Diagnosis and characterization of Leishmania species in Giemsastained slides by PCR-RFLP. Iran J Public Health. 2008;37(1):54-60.

14. Schonian G, Akuffo H, Lewin S, Maasho K, Nylen S, Pratlong F, et al. Genetic variability within the species Leishmania aethiopica does not correlate with clinical variations of cutaneous leishmaniasis. Mol Biochem Parasitol. 2000;106(2):239-48.

15. Schonian G, Schnur L, el Fari M, Oskam L, Kolesnikov AA, Sokolowska-Kohler W, et al. Genetic heterogeneity in the species Leishmania tropica revealed by different PCR-based methods. Trans R Soc Trop Med Hyg. 2001;95(2):217-24.

16. Cupolillo E, Momen H, Grimaldi GJ. Genetic diversity in natural populations of New World Leishmania. Mem Inst Oswaldo Cruz. 1998;93(5):663-8.

17. Schonian G, Nasereddin A, Dinse N, Schweynoch C, Schallig HD, Presber W, et al. PCR diagnosis and characterization of Leishmania in local and imported clinical samples. Diagn Microbiol Infect Dis. 2003;47(1):349-58.

18. World Health O. Control of the leishmaniases. World Health Organ Tech Rep Ser. 2010(949):xii-xiii-back cover.

19. Yang BB, Chen DL, Chen JP, Liao L, Hu XS, Xu JN. Analysis of kinetoplast cytochrome $b$ gene of 16 Leishmania isolates from different foci of China: different species of Leishmania in China and their phylogenetic inference. Parasit Vectors. 2013;6:32. 